\title{
Relação entre o verbal e o visual: leitura de uma gravura de Dürer, feita por Saramago
}




\section{Resumo}

O propósito central deste texto consiste em, a partir de alguns conceitos centrais da perspectiva teórica da semiótica da Escola de Paris, desenvolver uma análise da leitura que o narrador do texto $O$ evangelho segundo Jesus Cristo, de José Saramago, realiza de uma gravura produzida por Dürer. A hipótese básica deste trabalho é a de que a descrição da gravura de Dürer realizada pelo narrador remete, metonimicamente, à estrutura do romance como um todo.

\section{Palavras-chave}

discurso, enunciação, interdiscursividade, intertextualidade, narratividade, leitura

\section{Abstract}

The central purpose of this text consists in, by using some central concepts of theoretical semiotic perspective of the School of Paris, developing an analysis of the reading that the narrator of the text The gospel according to Jesus Christ, by José Saramago, does of a picture produced by Dürer. The basic hypothesis of this work is that the description of the mentioned picture done by the narrator refers, metonymically, to the romance structure as a whole.

Key words

discourse, enunciation, interdiscursivity, intertextuality, narrativity, reading process 


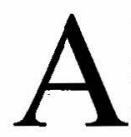

semiótica, enquanto teoria que está preocupada com a manifestação da significação, pretende dar conta dos textos verbais, dos não-verbais e dos sincréticos, isto é, daqueles que se valem tanto do código verbal quanto do nãoverbal para se constituírem. Perceber, portanto, como esses diferentes tipos de textos organizam sentidos faz parte do projeto semiótico, que concebe o plano de conteúdo dos textos sob a forma de um percurso gerativo.

O propósito deste trabalho não será discutir os postulados teóricos da semiótica, mas aplicar seus princípios para desenvolver a análise de um texto verbal que realiza a leitura de um outro não verbal. $\mathrm{O}$ texto verbal de leitura corresponde às oito primeiras páginas de abertura do romance $O$ evangelho segundo Jesus Cristo, de José Saramago e o não-verbal, a uma gravura sobre a paixão de Cristo, produzida pelo pintor alemão Albrecht Dürer, que viveu entre o final do século XV e o início do XVI (1471-1528).

Para dar conta do exame do texto de Saramago, que realiza uma leitura descritiva da gravura de Dürer, objetivo central deste trabalho, proporei dividi-lo em três partes. Na primeira, procurarei observar o desenho do pintor alemão, colocando-me na posição de um leitor de seu texto imagético. Na segunda, farei um brevíssimo comentário sobre o romance de Saramago em questão, procurando inserir as oito páginas que chamo de abertura no contexto da narrativa como um todo. Por último, deter-me-ei no exame do texto de abertura, com o objetivo de verificar como o sujeito enunciador interage com seu enunciatário ao manifestar sua leitura do texto de Dürer. 


\section{Mito cristão da crucificação de Jesus segun- do Dürer}

Dürer, embora fosse um alemão, nascido em Nuremberg, tinha incorporado a suas obras, pinturas, xilogravuras, gravuras, muito da técnica artística da escola veneziana. A época em que viveu correspondeu ao período de passagem da Idade Média para o

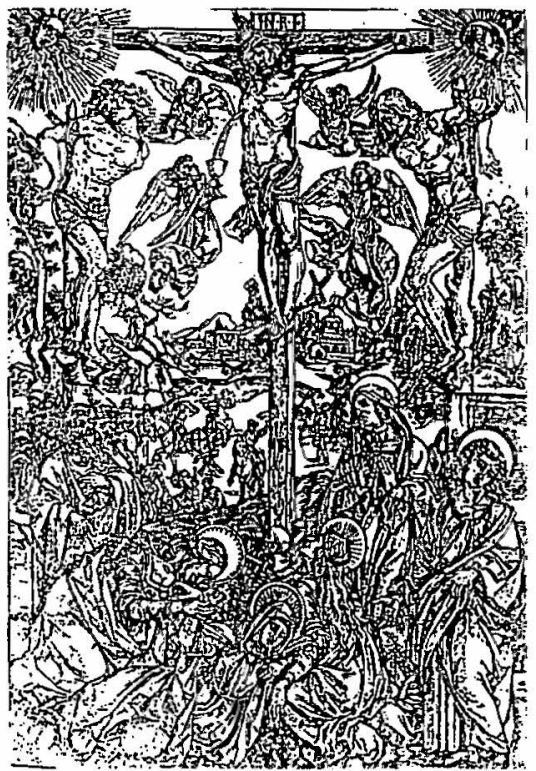

Figura 1

Renascimento europeu, tão marcante na produção cultural da Itália em geral. A influência dessa concepção renascentista pode ser notada na gravura de Dürer (figura 1), principalmente, na caracterização física dos seres animados por ele retratados. A preocupação em definir as formas do corpo de Jesus e dos dois ladrões crucificados, bem como dos cavalos que aparecem no plano de fundo da gravura, pode justificar a ótica renascentista por ele adotada para retratar a cena do calvário cristão. Na pintura e no desenho medieval, somente a expressão dos seres retratados (embora não completamente definida) e, por serem quase que exclusivamente divinos, a aura de santidade desses seres é que importa. As formas do corpo são completamente descaracterizadas e o que sobra nas pinturas medievais é centralização do espiritual em detrimento do humano.

Para dar uma idéia dessa concepção medieval da retratação dos corpos, comparo a gravura de Dürer com a cena da "Crucifixão" (figura 2), pintada por Fra Angélico, entre 1438 a 1443, num retábulo para o Mosteiro de São Marcos, da ordem dos dominicanos. Embora tenha vivido num período não muito distante do de Dürer, Fra 
Angélico (1387?-1455) tinha mais influências da arte medieval do que da renascentista que emergia. Comparando a cena retratada por Fra Angélico e a de Dürer, percebemos a simplicidade da primeira, pois não há fundo nem um contexto que situe o calvário de Jesus, em oposição à riqueza de detalhes da segunda. O Cristo de Dürer tem seu sexo coberto por um pano, enquanto o Cristo de Fra Angélico está completamente nu, mas sem o órgão sexual. Essa é outra marca da influência renascentista em Dürer e da medieval em Fra Angélico. Embora se possa falar de pudor na gravura de Dürer, pois o órgão sexual de Cristo está ocultado por panos, o simples fato de isso acontecer é significativo de que o gravurista admitia que Cristo tinha órgão sexual. Já, para Fra Angélico, o fato de Cristo estar nu e sem órgão genital também possa ser um indício de pudor, essa forma de reprodução da figura de Jesus adquire um sentido maior dentro do contex to do pensamento cristão: a idéia de divindade; um ser divino não tem sexo, porque não é igual aos seres humanos.

Em nenhum momento fiz referências ao aspecto cromático da pintura de Fra Angélico, que também está ligado à concepção da arte medieval, porque não é possível compará-lo com a gravura de Dürer, pois ela não tem cor.

Se voltarmos nossa atenção novamente para a gravura do pintor alemão, poderemos observar que ela tem bastante acentuado o trabalho com planos de perspectiva. De uma forma geral, poderia dizer que existe um primeiro plano, que é o que está na parte da frente do desenho, correspondente às figuras humanas que parecem sofrer com a morte de Cristo e os três crucificados (Jesus, o bom e o mau ladrão). O segundo plano, que é o que está no fundo do

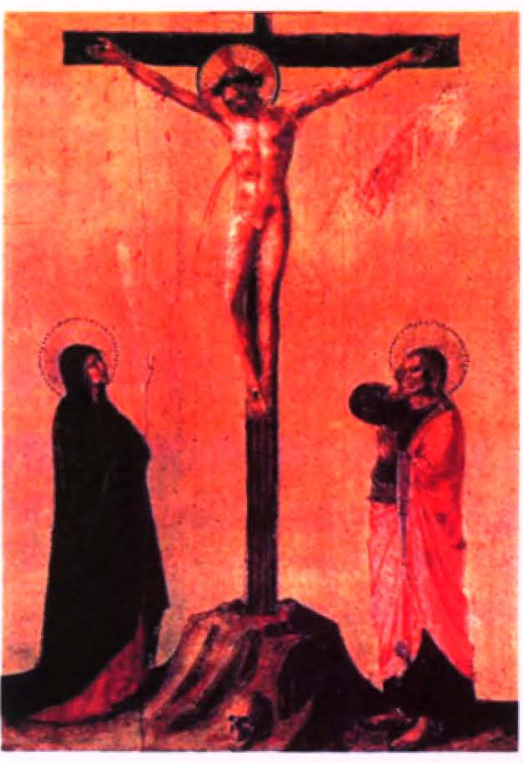

Figura 2 
desenho, depois da cena do primeiro, corresponde às figuras de alguns soldados a cavalo e outros a pé, um homem com um balde na mão esquerda e uma vara na direita, vegetação, algumas construções e montanhas. Ao redor do corpo de Cristo, quatro anjos pairam no ar. Um que parece estar mais próximo a ele, pois segura uma taça onde cai seu sangue e outros três que parecem estar flutuando entre o primeiro e o segundo plano. Nos cantos superiores do desenho aparece o sol, à direita de Jesus, e a lua, à sua esquerda.

Do ponto de vista da organização do desenho pode-se dizer que ele reproduz um semi-círculo, ou melhor, a forma de um "U". No centro está a cruz e Jesus pregado a ela, que ocupa praticamente todo o desenho. Só não divide o desenho em dois lados, desde a base até o alto, porque abaixo da cruz aparece a figura de três mulheres, uma das quais Maria, mãe de Jesus, quase desfalecida pela dor da perda do filho. Do lado direito de Jesus está um dos ladrões que olha para os céus; de seu lado esquerdo está o outro ladrão que olha para baixo. Tudo, no primeiro plano do desenho, converge para o centro. Até o sol e a lua, representados por rostos humanos, parecem sofrer com a morte do filho de Deus. Ao fundo, tudo o que ali se passa parece estar distante da cena do primeiro plano. Se os soldados a cavalo e a pé e o homem com o balde participaram da crucificação de Jesus, agora parecem estar ocupados com outras coisas.

Os sentidos que a gravura adquire são determinados pela espacialidade do primeiro plano, em que predominam as oposições entre alto e baixo, centro e margem, vida e morte. O corpo de Jesus, em destaque no centro do desenho, ocupa a posição mais alta; suas mãos parecem próximas do sol e da lua. E a cena retrata a morte de Jesus que, segundo a tradição cristã, representou a salvação da humanidade do pecado. Enquanto representação de um estado, o que é característico do desenho, da pintura e da fotografia, a gravura de Dürer pressupõe um antes e um depois, ou seja, o julgamento e condenação de Jesus e seu sepultamento e ressurreição. É nessa tensão entre o antes e o depois que o desenho ganha movimento, pois isso o coloca na sequiência narrativa própria de todo e qualquer texto. Ele retrata um momento que o leitor (sujeito que vê a gravura) identifica. 
O que se deve levar em consideração, então, quando se olha para o desenho de Dürer é que ele é o resultado de uma leitura que o autor faz da passagem bíblica da crucificação de Jesus. O pintor alemão retratou a cena a partir da descrição que dela aparece nos quatro evangelhos canônicos que constituem o Novo Testamento. Portanto, o leitor da gravura, que também foi leitor do tex to bíblico, compreende aí aquilo que faz parte do seu saber, ou seja, a história da vida de Jesus. $\mathrm{O}$ ato de olhar para a gravura de Dürer consiste, portanto, em ler a leitura que o desenhista faz de uma passagem bíblica.

Se olharmos diretamente para o texto bíblico, será possível até identificar melhor as personagens que aparecem retratadas no desenho. Em primeiro lugar, reconhecer que é Jesus que está crucificado no centro do desenho e que, a seu lado, estão os dois ladrões, o bom e o mal, só é possível para quem conhece a passagem bíblica. Em segundo lugar, identificar Maria, mãe de Jesus, e outras pessoas que estavam ao pé da cruz na hora de sua morte, só é possível se eu retomar o texto bíblico. Dos quatro evangelhos canônicos, Mateus, Marcos e João indicam nomes das pessoas que estavam junto à cruz de Jesus. $\mathrm{O}$ evangelho de Lucas diz apenas que seus familiares estavam com ele. $O$ crânio na base da cruz, que pode ser observado tanto no desenho de Dürer quanto na pintura de Fra Angélico, justifica-se porque, em todos os evangelhos do Novo Testamento, explica-se para o leitor que o lugar para onde Jesus foi levado para ser crucificado chamava-se Gólgota que, em hebreu, significava crânio.

\section{O evangelho de Saramago}

$\mathrm{O}$ texto do romance de Saramago corresponde à reconstituição da história da vida de Jesus Cristo, desde seu nascimento até sua morte. Do ponto de vista enunciativo, ocorre uma debreagem enunciva em que uma terceira pessoa narra os fatos marcados num tempo do então e num espaço do lá, o que justifica, portanto, a debreagem temporal e espacial também enunciva.

A narrativa do evangelho de Saramago é diferente da dos evangelhos canônicos do Novo Testamento, na medida em que não fala de Jesus e de sua família como se esta fosse santa e aquele, 
um ser divino. $\mathrm{O}$ tom da narrativa desse evangelho é marcado pela crueza e naturalidade no relato dos fatos. José, Maria e Jesus parecem não entender direito o que estão vivendo, embora acreditem num Deus e o temam.

Durante uns poucos de anos não houve mais mudanças na família que nascerem novos filhos, além de duas filhas, e terem perdido os pais deles o último viço que lhes ficara da juventude. Em Maria não havia que estranhar, pois sabe-se como as prenhezes, e de mais sendo tantas, acabam por dar cabo duma mulher, vai-se-lhes aos poucos a beleza e a frescura, se as tinham, emurchecem tristemente a cara e o corpo, basta ver que depois de Tiago nasceu Lísia, depois de Lísia nasceu José, depois de José nasceu Judas, depois de Judas nasceu Simão, depois Lidia, depois Justo, depois Samuel, e se mais algum veio, logo se finou, sem tempo de deixar registro. Os filhos são a alegria dos pais, diz-se, e Maria fazia tudo para parecer contente, mas, tendo de carregar meses e meses no seu cansado corpo tantos frutos gulosos das suas forças, às vezes entrava-lhe na alma uma impaciência, uma indignação à procura da sua causa, mas, sendo o tempo o que era, não pensou em pôr culpas a José, e menos ainda àquele Deus supremo que decide da vida $e$ da morte das suas criaturas, a prova é que mesmo um cabelo da nossa cabeça não cai se não for de sua vontade. (Saramago, 1999, pp. 139-40)

O Jesus de Saramago é um ser humano sem nenhuma aura de divino; sente raiva, remorso, prazer, comete erros como qualquer homem comum. O processo por meio do qual vai sendo convencido de que é filho de um Deus e que deve salvar os homens é lento e, mesmo no momento da crucificação ele parece não entender direito por que tinha que passar pelo que estava passando. As noções de bem e mal são muito instáveis e, em várias passagens da narrativa, a bondade de Deus e a maldade do Diabo são questionadas, chegando ao ponto, quando o Diabo faz uma proposta a Deus, em que o comportamento deste parece revelar uma tirania superior à daquele. 
(...) Propõe lá (diz Deus ao diabo), mas depressa, que não posso ficar aqui eternamente, Tu sabes, ninguém melhor do que tu o sabe, que o Diabo também tem coração, Sim, mas fazes mau uso dele, Quero hoje fazer bom uso do coração que tenho, aceito e quero que o teu poder se alargue a todos os extremos da terra, sem que tenha de morrer tanta gente, e pois que de tudo aquilo que te desobedece e nega, dizes tu que é fruto do Mal que eu sou e ando a governar o mundo, a minha proposta é que tornes a receber-me no teu céu, perdoado dos males passados pelos que no futuro não terei de cometer, que aceites e guardes a minha obediência, como nos tempos felizes em que fui um dos teus anjos predilectos, Lúcifer me chamavas, o que a luz levava, antes que uma ambição de ser igual a ti me devorasse a alma e me fizesse rebelar contra a tua autoridade, $E$ por que haveria eu de receber-te e perdoar-te, não me dirás, Porque se o fizeres, se usares comigo, agora, daquele mesmo perdão que no futuro prometerás tão facilmente à esquerda $e$ à direita, então acaba-se aqui hoje o Mal, teu filho não precisará morrer, o teu reino será, não apenas esta terra de hebreus, mas o mundo inteiro, conhecido e por conhecer, e mais do que o mundo, o universo, por toda a parte o Bem governará, e eu cantarei, na última e humilde fila dos anjos que te permaneceram fiéis, mais fiel então do que todos, porque arrependido, eu cantarei os teus louvores, tudo terminará como se não tivesse sido, tudo começará a ser como se dessa maneira devesse ser sempre, Lá que tens talento para enredar almas e perdêlas, isso sabia eu, mas um discurso assim nunca te tinha ouvido, um talento oratório, uma lábia, não há dúvida, quase me convencias, Não me aceitas, não me perdoas, Não te aceito, não te perdôo, quero-te como és, $e$, se possivel, ainda pior do que és agora, Porquê, Porque este Bem que eu sou não existiria sem esse Mal que tu és, um Bem que tivesse de existir sem ti seria inconcebivel, a 
um tal ponto que nem eu posso imaginá-lo, enfim, se tu acabas, eu acabo, para que eu seja o Bem, é necessário que tu continues a ser o Mal, se o Diabo não vive como Diabo, Deus não vive como Deus, a morte de um seria a morte do outro, É a tua última palavra, A primeira e a última, a primeira porque foi a primeira vez que a disse, a última porque não a repetirei. (Saramago, 1999, pp. 392-3)

A perspectiva a partir da qual o enunciador do texto de Saramago produz seu discurso desfaz completamente a narrativa canônica da bíblia. Ao invés de contar a vida de Jesus para provar sua santidade, esse enunciador, manifestando sempre seu ponto de vista, que é o de um homem do século XX, conhecedor de toda a história de guerras e mortes em função da causa religiosa, retira do texto sagrado seu caráter de verdade absoluta. O enunciador de Saramago sempre instiga seu enunciatário, o leitor implícito no texto, a pensar na história que ele conta como possivelmente mais verdadeira que a do tex to bíblico. É exatamente esse diálogo entre o enunciador e o enunciatário o responsável por toda a argumentação que sustenta a narrativa de Saramago.

Como esse enunciador, portanto, está mais preocupado em discutir os limites da crença religiosa, faz com que o narrador em que se projeta termine a história de Jesus exatamente no momento em que ele morre na cruz; nada é dito sobre seu sepultamento e posterior ressurreição. Assim, a gravura de Dürer, descrita e comentada no início do romance, funciona como uma antecipação da cena final com a qual o narrador terminará sua história. Por meio de seu comentário sobre essa gravura, o narrador irá revelar o ponto de vista a partir do qual recontará a história da vida de Jesus.

\section{A leitura da gravura de Dürer: comentários de um narrador}

A leitura da gravura de Dürer que abre o romance de Saramago, ao mesmo tempo em que é uma descrição, é também um 
comentário-crítico sobre o que está sendo representado. O sujeito que enuncia no texto mostra seu ponto de vista quando faz considerações sobre o que no desenho uma determinada cena quis representar e o que ele conhece por meio da história.

O movimento descritivo da gravura parte, tomando como perspectiva o olhar do espectador, do canto superior esquerdo para chegar até o canto superior direito, desenhando a forma de um " $U$ ", tal como ficou sugerido no item 1 deste trabalho. A primeira observação feita pelo enunciador é a que revela o caráter irreal da cena mostrada, isto é, o fato de ser apenas uma gravura, uma representação que é fruto da imaginação de quem desenha. Isso pode ser observado em:

(...) e essa cabeça (do sol) tem um rosto que chora, crispado de uma dor que não remite, lançando pela boca aberta um grito que não poderemos ouvir, pois nenhuma destas coisas é real, o que temos diante de nós é papel e tinta, mais nada. (Saramago, 1999, p. 13)

Para identificar o Bom Ladrão, primeira imagem do crucificado, logo abaixo do sol, o enunciador chama a atenção do enunciatário para duas características daquela figura: seu olhar de sofrimento e seus cabelos encaracolados.

(...) Pela expressão da cara, que é de inspirado sofrimento, e pela direcção do olhar, erguido para o alto, deve de ser $o$ Bom Ladrão. $O$ cabelo, todo aos caracóis, é outro indício que não engana, sabendo-se que anjos $e$ arcanjos assim $o$ usam, e o criminoso arrependido, pelas mostras, já está no caminho de ascender ao mundo das celestiais criaturas. (Saramago, 1999, p. 13)

Em contraposição à descrição do Bom Ladrão, que tinha um tom irônico, mais à frente, em sua descrição, o enunciador do texto caracteriza o Mau Ladrão como aquele que é mais verdadeiro, pois não quis fingir arrependimento das ações cometidas no momento em que estava prestes a morrer. Sua figura se contrapõe à do Bom 
Ladrão na medida em que seu olhar se dirige para baixo e seus cabelos são lisos e não encaracolados como dos anjos.

(...) Magro, de cabelos lisos, de cabeça caída para a terra que o há-de comer, duas vezes condenado, à morte $e$ ao inferno, este misero despojo só pode ser o Mau Ladrão, rectíssimo homem afinal, a quem sobrou consciência para não fingir acreditar, a coberto de leis divinas e humanas, que um minuto de arrependimento basta para resgatar uma vida inteira de maldade ou uma simples hora de fraqueza. (Saramago, 1999, p. 17)

A caracterização positiva do Mau Ladrão e a negativa do Bom será retomada, mais à frente, quando o enunciador descreve a figura de Jesus Cristo crucificada no centro do desenho. Segundo ele, o filho de Deus é incapaz de perceber a diferença entre o Bem e o Mal enquanto forças dependentes. Nesse sentido, chamamos a atenção para o destaque que demos no item 2 deste trabalho para o diálogo entre Deus e o Diabo acerca das noções de Bem e Mal, ilustrado em Saramago, 1999, pp. 392-3. A crítica do enunciador em relação à incapacidade de Jesus para compreender a dependência que existe entre o Bem e o Mal parece ser uma questão central do texto de Saramago, uma forma dialética de entender o mundo, própria da visão do homem contemporâneo.

É ele (Jesus), finalmente, este para quem apenas olham José de Arimateia e Maria Madalena, este que faz chorar o sol e a lua, este que ainda agora louvou o Bom Ladrão e desprezou o Mau, por não compreender que não há nenhuma diferença entre um e outro, ou se diferença há, não é essa, pois o Bem e o Mal não existem em si mesmos, cada um deles é somente a ausência do outro. (Saramago, 1999, p. 18)

Esse mesmo tom bastante pessoal e crítico, ao comentar o desenho que o enunciador vê e pressupõe que o enunciatário também veja, mantido em relação à caracterização do Bom e do Mau 
Ladrão, persiste em todo o texto. Da mesma forma, ao descrever Maria Madalena, o enunciador aponta para um saber que crê compartilhar com seu enunciatário. Quando supõe que a primeira figura de mulher, olhando o desenho da esquerda para a direita, que segura a mão de Maria, é Maria Madalena, vale-se do fato de ela apresentar um decote muito acentuado, o que permite que seus seios fiquem à mostra para chamar a atenção dos homens. Esse fato, segundo ele, só pode ser característico de uma mulher como Madalena que, segundo o relato bíblico, foi uma prostituta.

Mas, ao continuar a descrever as figuras femininas que estão ao pé da cruz de Jesus, tentando, num apelo explícito ao enunciatário, identificá-las, o enunciador se depara com a terceira mulher, nas coxas de quem Maria, mãe de Jesus, apóia seu braço esquerdo. Ao deter seu olhar sobre ela, o enunciador do texto levará em consideração dois aspectos para determinar que ela era a verda-; deira Maria Madalena e não a primeira mulher que sustenta as mãos de Maria: seu olhar e a cor de seus cabelos.

Esse jogo irônico sobre a cor dos cabelos de Maria Madalena é outro indício que aponta a contemporaneidade do enunciador, pois remete a algo que é da cultura ocidental moderna. Ao mesmo tempo, suas considerações sobre o olhar da mulher ajoelhada são extremamente subjetivas, na medida em que nada, no desenho, identifica que o olhar daquela terceira mulher seja um olhar apaixonado, mais carnal que espiritual. Nesse momento, o enunciador parece fazer uma brincadeira com o enunciatário, pois irá se valer da leitura que faz do olhar dessa mulher para dizer que ela, sem dúvida, é a verdadeira Maria Madalena.

(...) Tal como a primeira desta trindade de mulheres, mostra os longos cabelos soltos, caídos pelas costas, mas estes têm todo o ar de serem louros, se não foi pura causalidade a diferença do traço, mais leve neste caso e deixando espaços vazios no sentido das madeixas, o que, obviamente, serviu ao gravador para aclarar o tom geral da cabeleira representada. Com tais razões não pretendemos afirmar que Maria Madalena tivesse sido, de 
facto, loura, apenas nos estamos conformando com a corrente de opinião maioritária que insiste em ver nas louras, tanto as de natureza como as de tinta, os mais eficazes instrumentos de pecado e perdição. Tendo sido Maria Madalena, como é geralmente sabido, tão pecadora mulher, perdida como as que mais o foram, teria também de ser loura para não desmentir as convicções, em bem e em mal adquiridas, de metade do género humano. Não é, porém, por parecer esta terceira Maria em comparação com a outra, mais clara na tez e no tom do cabelo, que insinuamos e propomos, contra as arrasadoras evidências de um decote profundo e de um peito que se exibe, ser ela a Madalena. Outra prova, esta fortíssima, robustece e afirma a identificação, e vem a ser que a dita mulher, ainda que um pouco amparando, com distraída mão, a extenuada mãe de Jesus, levanta, sim, para o alto o olhar, e este olhar, que é de autêntico $e$ arrebatado amor, ascende com tal força que parece levar consigo o corpo todo, todo o seu ser carnal, como uma irradiante auréola capaz de fazer empalidecer o halo que ja lhe está rodeando a cabeça e reduzindo pensamentos e emoções. Apenas uma mulher que tivesse amado tanto quanto imaginamos que Maria Madalena amou poderia olhar desta maneira, com o que, derradeiramente, fica feita a prova de ser ela esta, só esta, $e$ nenhuma outra (...). (Saramago, 1999, p. 16-7)

Uma última prova da subjetividade do enunciador, com que se encerra essa apresentação do romance de Saramago, está nas considerações que ele faz a respeito de uma personagem que aparece no segundo plano do quadro, a do homem que carrega um balde e uma cana em cada uma das mãos. Novamente, esse enunciador de Saramago irá se valer de um saber histórico para criticar a maneira como se tem interpretado um fato específico que ocorre durante a crucificação de Jesus. Trata-se da oferta de vinagre a Jesus quando ele reclamou sentir sede. Segundo se costuma interpretar, isso é um 
indício da maldade dos soldados que haviam sido incumbidos de crucificá-lo, pois o vinagre está associado, em nossa cultura ocidental moderna, àquilo que é impróprio para beber, devido a seu gosto azedo. Mas, conforme relata o enunciador, esse não era o costume da época em que Jesus viveu; ao contrário, toda vez que uma pessoa sentia muita sede, a forma de aplacá-la era tomar vinagre diluído em água. E é para isso que o enunciador chama a atenção de seu interlocutor, pois o conhecimento desse fato histórico transforma a figura do homem que ofereceu vinagre a Jesus e aos dois ladrões crucificados, que está associada sempre ao mal, a seu oposto, ou seja, ao bem.

(...) Lá atrás, no mesmo campo onde os cavaleiros executam um último volteio, um homem afasta-se, virando ainda a cabeça para este lado. Leva na mão esquerda um balde e uma cana na mão direita. Na extremidade da cana deve haver uma esponja, é difícil ver daqui, e o balde, quase apostaríamos, contém água com vinagre. Este homem, um dia, e depois para sempre, será vítima de uma calúnia, a de, por malícia ou escárnio, ter dado vinagre a Jesus ao pedir ele água, quando o certo foi ter-lhe dado da mistura que traz, vinagre e água, refresco dos mais soberanos para matar a sede, como ao tempo se sabia e praticava. Vai-se embora, não fica até ao fim, fez o que podia para aliviar as securas mortais dos três condenados, e não fez diferença entre Jesus e os Ladrões, pela simples razão de que tudo isto são coisas da terra, que vão ficar na terra, e delas se faz a única história possível. (Saramago, 1999, p.19-20)

Essa e muitas outras passagens da narrativa dizem respeito a uma das grandes características dessa versão do evangelho de Jesus criado pelo romance de Saramago, qual seja, um olhar contemporâneo sobre os fatos contados nos evangelhos canônicos sem o sentimento de religiosidade que neles está impregnado. O narrador de Saramago procura desvendar o texto mítico e mostrá-lo como um texto histórico. 
Para finalizar os comentários que apresentei aqui sobre a leitura que o enunciador do romance de Saramago faz da gravura de Dürer, chamo a atenção para um último aspecto da escrita dessa leitura. É possível observar em Saramago, 1999, p.19-20 a presença de dois termos grifados. São dois dêiticos que servem para localizar no espaço da gravura aquilo que o enunciador está enfocando.

É interessante observar que, no caso de este, o dêitico indica uma direção, como se o enunciador estivesse junto do enunciatário e pudesse identificar um dos lados da gravura, que corresponde ao primeiro plano, do qual enunciador e enunciatário estão mais próximos. Na realidade, o homem que carrega o balde e a cana, ao fundo, parece estar olhando para a cruz em que Jesus ficou pregado. Como quem olha para a gravura está de frente para as cruzes, o olhar do homem parece estar dirigido para fora dela, o que pode denunciar uma cumplicidade entre ele e aqueles que olham para o desenho.

$\mathrm{O}$ uso de daqui também chama a atenção na medida em que indica claramente o lugar onde está o enunciador. É ele que diz que não consegue enxergar direito do lugar onde está (daqui) para o balde que o homem carrega no segundo plano do desenho. Novamente, a forma de uso desses dêiticos, que também aparecem em vários outros trechos dessa abertura da narrativa de Saramago, cria o efeito de sentido de proximidade entre a instância do enunciador e a do enunciatário, que cobrem explicitamente as figuras do "autor" (narrador) e seu "leitor" (narratário).

\section{Conclusão}

O propósito deste trabalho foi observar como os sentidos de um texto de leitura se constroem e, ao mesmo tempo, perceber os sentidos investidos no texto que dá origem à leitura. Da mesma forma que posso dizer que o texto escrito é capaz de comunicar algo a um leitor porque constrói a significação daquilo que diz a partir da relação entre os diferentes elementos que o constituem, o texto nãoescrito, ou figurativo, no caso da gravura de Dürer, também o faz. A disposição das personagens, o enfoque de certos detalhes, a organização dos diferentes planos, a intensidade dos traços, todos esses 
elementos contribuem para o sentido que a gravura adquire e transmite a quem a vê. O observador da gravura pode se aproximar dela a partir de um determinado ponto e assim ir reconstruindo o que $o$ desenho pretende comunicar.

Por outro lado, o que procurei salientar durante minha análise desse desenho foi que ele pressupõe que o sujeito que o vê conheça a história bíblica da vida de Jesus, pois, como mostrei, ele é fruto da leitura do evangelho do Novo Testamento. Isso significa colocar, então, uma vez mais, que a própria produção de um texto é dependente de relações interdiscursivas, ao repetir determinada formação discursiva, e, em alguns casos, também intertextuais, quando remete, explícita ou implicitamente a outros textos.

\section{Bibliografia}

BARROS, Diana Luz Pessoa de. 1988. Teoria do discurso. São Paulo: Atual. 1990. Teoria semiótica do texto. São Paulo: Ática.

BERRINI, Beatriz (org.). 1999. José Saramago. Uma homenagem. São Paulo: EDUC/FAÉSP.

FIORIN, José Luiz. 1989. Elementos de análise do discurso. São Paulo: Contexto/Edusp. (Repensando a Língua Portuguesa).

GREIMAS, Algirdas Julien. 1987. De l'imperfection. Périgueux: Pierre Fanlac.

GREIMAS, Algirdas Julien \& FONTANILLE, Jacques. 1993. Semiótica das paixões. Dos estados de coisas aos estados de alma. Trad. De Maria José Rodrigues Coracini.São Paulo: Ática.

SARAMAGO, José.1999. O evangelho segundo Jesus Cristo. São Paulo: Companhia das Letras.

SILVA, Ignácio Assis. 1997. Figurativização e metamorfose. Relações intersemióticas (O mito de Narciso). São Paulo: Ed. UNESP. 